\title{
A Content Analysis On the Quality of Short Stories in Short Stories For Children's Published By Children's Book Trust
}

\author{
Citra Ayu Rahmatika \\ English Educational Department, PGRI University of Banyuwangi
}

\begin{tabular}{ll} 
Received & $:$ Wednesday, October 10, 2018 \\
Revised & $:$ Tuesday, October 23, 2018 \\
Accepted & : Monday, October 29, 2018 \\
\hline
\end{tabular}

\section{Abstract}

Reading is one of the language skills. There are four components of the language skills are: listening, speaking, reading, and writing. Reading is one of the important skills in teaching English. In this research, the researcher is interested to discuss about a content analysis on the quality of short stories in short stories for children's published by children's book trust. The purpose of this research are to measure the quality of short stories in short stories for children's published by children's book trust, and to identify the readability and gender equality of short stories for children's published by children's book trust. The design of this research was descriptive qualitative research. To get the data of the research, The researcher used a documentation. The researcher used flesch reading ease formula. The data sources from this research taken from book entitled short stories for children's published by children's book trust. In this book consist of 17 titles from 17 authors. Based on the result of the data analysis of documentation, it can be known that all of short story can be read by children from the age $8-11$ years old. Types of reading level in this short stories are easy and very easy. From the 17 short stories, total number of short stories that tell about men life there were 12. While total number of short stories that tell about women life there were The researcher concluded that the quality of short stories for children's published by children's book trust is enough. The readability of short stories in short stories for children's published by children's book trust is easily understood by children's and all short stories are suitable as children's books. The gender equality in short stories for children's published by children's book trust is gender bias. The short stories only focus on one gender. The suggestion are for the readers, the researcher suggest that the readers can selecting to choose short stories which is most suitable to reading. The reader can also apply the result of this study as feedback on their reading activities, improve their knowledge and experience in choosing appropriate book, so that the reader is better in reading skill. For the other researchers, it would be useful for the other researcher to use the result as additional reference for those who want to conduct research. The researcher suggest that the other researchers can add research on the short story 


\section{A. Introduction}

English is the first foreign language in Indonesia. In this globalization era, English is very important to be mastered because it becomes an international language. It means that, it is used for communication by the people around the world. Nowadays, there are many kinds of information media, such as TV, radio, magazine, newspaper, book and also internet use English to transmit information. So, besides it is used as communication medium by people with another, it is also used by many kind of information or news. In brief, by mastering English the people can obtain a lot of information either it is in written or spoken forms and establish relationship with the people among countries.

Actually, there are four skills in English that should be learned by students. Those are reading, listening, speaking and writing. Reading is one of an English skill which make the students be able to enrich their knowledge. By comprehend reading, they will get lot of information about what they read. The next skill is listening. Listening skill only focuses on hearing and getting the idea of what the speaker says. Besides that, to increase the students ability in hearing, this skill also will help them to know how to pronounce a certain word appropriately. Another skill is speaking. Speaking is the most particular way to express idea and opinion. By practicing to speak more and more, someone will be able to speak more fluently and has good performance in spelling or pronouncing

word. The last skill is writing. In writing, grammar, the creativity to think, and ability in choosing appropriate word are absolutely needed, in order the content of writing is communicative, clear and understandable by the reader. All of four English skills are very important and should be mastered as good as possible by the students.

From the fourth language skills, the researcher takes one of the four skills, that is reading. Reading is a process in which the reader reconstructs a message which has been encoded by a writer. Reading as an active process of comprehending where the students need to be taught strategies to read more efficiently, guess from context, define expectations, make inferences about the text, skim ahead to fill in the context. By such a definition, it can be said that reading can be seen as an interactive process between a reader and a text which leads to automaticity or reading fluency. In this process, the reader interacts dynamically with the text, tries to elicit the meaning and various kinds of knowledge are being used linguistic knowledge or systemic knowledge and schematic knowledge. According to Alyousef (2005:144) There are six general component in reading process, namely : automatic recognition skills, vocabulary and structural knowledge, formal discourse structure knowledge, content or word background knowledge, synthesis and evaluation skills or strategies and metacognitive knowledge and skills monitoring.

By reading activity, people may gain important information that are not presented. It means that the cognitive model, people as readers are more than passive participants who receive information while an active text makes itself and its meanings known. Actually, the act of 
reading is a push and pull between reader and text. According to Fauziati (2009:34) during the reading, the reader processes his background knowledge and the printed text using specific skills and strategies to form expectations or predictions about the text, selecting and using the most productive cues to confirm or reject those predictions. Therefore, it can be concluded that the reader in reading, constructs a message which is encoded by writer, in cyclical process of sampling from the input text, predicting, testing, and confirming or revising these predictions.

In reading, the readers not only read and understand the text but also they have to know the quality and criteria of texts. For the reader, knowing the quality and criteria from the book will make them understand about reading. To compare a good reading material and for teacher can use the reading as additional reference to teaching reading comprehension

\section{Research Problem}
a. General Problem
How is the quality of short stories in short stories for children's published by children's book trust?

\section{b. Specific Problem}
How is the readability of short stories in short stories for children's published by children's book trust?
How is the gender equality in short stories for children's published by children's book trust?

\section{Objective of the Research}

\section{a. General Objective}

To measure the quality of short stories in short stories for children's published by children's book trust.

\section{b. Specific Objective}

To identify the readability of short stories in short stories for children's published by children's book trust.

To identify the gender equality in short stories for children's published by children's book trust

\section{Significance of the Research}

It is hoped that the result of the research in short stories book published by children's book trust can be useful in term to the readers and the other researcher.

For the readers, it is hoped that result will give an information in selecting short stories which is most suitable to reading. The reader can also apply the result of this study as feedback on their reading activities, improve their knowledge and experience in choosing appropriate book, so that the reader is better in reading skill.

Besides that, it would be useful for the other researcher because it can improve the researcher knowledge about the gender equality and readability in content analysis. And the other researcher can use the result as additional reference for those who want to conduct research. 


\section{The Scope and Limitation of the Research}

In this study, the researcher limits the discussion about a content analysis of short stories book published by children's book trust. It measures the quality of short stories book by identifying readability of short stories book and gender equality in short stories book published by children's book trust.

\section{Definition of Key terms}

a. Content Analysis

Content analysis is a method that may be used with either qualitative or quantitative data and in an inductive or deductive way. Cole (in satu elo \& helvi kyngas, 2008:107) stated that content analysis is method of analysis of written, verbal or visual communication message. In this research, content analysis as a method to collect relevant information from short stories. There parts of content analysis such us lexical density, authenticity, readability, and gender equality. From this part the researcher will identify the readability and gender from the short stories.

b. Short Stories

The definition of short stories in this research is a short stories designed for children which is published by children's book trust.

\section{B. Literature}

Literature is more focused and restricted to merely imaginative works, which comes up from the imaginative mind of the story writers. Klarer (2004:1) stated that in most cases, literature referred to as the entirety of written expression, with the restriction that not every written document can be categorized as literature in the more exact sense of the word. The definitions, therefore, usually include additional adjectives such as aesthetic or artistic to distinguish literary works from texts such as newspapers, scientific textbooks, magazines, legal documents, brochures, and so on. Literature can be said as a creative writing by an author with aesthetic values which makes literature regarded as an art. Literature as a writing form differentiates its form from other art products, and its aesthetic or artistic values make it different from other writings.

Literature has three general genres, they are Drama, Poetry, and Prose. The word drama is derived from the Greek word dran means to do or to act. Poetry is created in various forms and the classification is based either on technique of writing or content. The word prose is derived from the Latin prosa, which literally translates to straightforward. Prose is the ordinary form of written language. Prose is adopted for the discussion of facts and topical reading, as it is often articulated in free form writing style. Classify prose into two, fiction prose and nonfiction prose. Fiction, originally meant anything made up or shaped, it is prose stories based on the author's creation and imagination. It includes myths, parables, novels, romances, and short stories. On the other hand, nonfiction is

literary works which describe or interpret facts, present judgments, and opinions It consists of news reports, essays, magazines, newspapers, 
encyclopedias, broadcast media, films, letters, historical and biographical works and many other forms of communication.

\section{Short Stories}

Definition of short stories is a relatively short stories and communicating complex life events. Event of story based on events in community. Short stories tend to be less complex than novels. Usually, a short story will focus on only one incident, has a single plot, a single setting, a limited number of characters, and covers a short period of time. On the other hand reading short stories is enjoyable and be hooked because short stories are little and always entertains the reader. Reading short stories does not make the reader bored.

Short stories have some characteristics that are different from the other story. Characteristic of short stories are devided into two elements. There are intrinsic elements and extrinsic elements. In intrinsic elements there are six elements. The first is character, in character there are main character, additional figures, protagonist, and antagonist. The second is theme. Theme can be interpreted as a subject matter in the story. The third is background of story. There are three elements in background of story such as place, times, and social. The fourth is plot, there are three elements in plot such as events, conflict, and climax. Fifth is point of view, and the last is suggestion. On the other hand extrinsic elements are the background of the community, the background of the author, biographies, psychological, and genre. First, the background of the community is that a movement of the people against the formation of a storyline. Second, the background of the author can include understanding the history of life from the author or historical have been made before. Third is biographies. Biographies usually contains biographical of the author that was written as a whole. Fourth is psychological. Psychological condition is about understanding the mood when the author writes the story. Finally, is genre. The author will certainly follow a particular literary genre. it is extremely influential on the style of writing used by the author in creating a story in the short storyln short stories there are some text structure. The first is abstraction. This part explains about summary or core of story. The second is orientation. It tells about background of story such as place and times. The third is complication, complication is the event of the story that introduces the conflict. After that is evaluation. It is completion and problem solving. Next resolution, resolution is the point of the story when conflict is resolved. The last is coda or moral.

The language of short stories has a dual role. It not only serves as a transmitter idea of the authors, but also as a transmitter of feelings. The authors not only tells to the reader about what is done and experienced figure of the story, but also intends to invite the reader to participate and feel what is felt by the characters. In short stories there are also some types of short stories. They are mini short stories with number of words between 750 until 1.000, ideal short 
stories with number of words between 3.00. until 4.000, and long short stories with number of words reach 10.000 .

\section{Aspect of Good Reading Material}

There are some aspects of good material such as gender equality, readability, lexical density, and authenticity:

a. Readability

Readability is an attempt to match the reading level of written material to the comprehension level of the readers. This increasingly demands a high level of comprehension and the application of knowledge, rather than a simple ability to recognize letters and decode words. Readability is concerned with the problem of matching between reader and text. An accomplished reader is likely to be bored by simple repetitive texts. A poor reader will soon become discouraged by texts which she or he finds too difficult to read fluently. This is likely to happen when the text is poorly printed, contains complex sentence structures, long words or too much material containing entirely new ideas. The term readability refers to all the factors that affect success in reading and understanding a text. These factors are the interest and motivation of the reader, the legibility of the print, and the complexity of words and sentences in relation to the reading ability of the reader.

b. Gender Equality

In many cultural contexts, the differences between girls and boys, and between men and women, are regarded as natural. Children are classified at birth usually by observing their genitals into two categories: male and female. On the basis of the category to which they belong, society will consider them qualified to do certain things and expect certain attitudes and behavior of them. Their rights and duties and their social, economic and political roles will be different during their childhood and throughout their adult lives. All societies are organized around this basic social differentiation, which dominates the life of individuals to a considerable extent. Based on the statement definition of gender is related to culture and the social division into masculine and feminine. Gender therefore pertains to the qualities, tasted, aptitudes, roles, and responsibilities associated

with men and women in a society. Definition of masculine and feminine is very enormously, demonstrating the social origin, since every society develops its classification on the basis of its own criteria and principle. The concept of masculinity and femininity are not developed independently of each other but are mutually dependent. In reading material, learning material presented in the book can be either a narrative text or illustrations. However, from books are used as teaching materials in schools many contain text and illustrations of gender bias. The examples of exemplarily shown in the text or pictures in these 
books often represent the role, nature, and status of gender bias. Generally, women appear in the role of domestic, feminine and in a position of subordination. While men more displayed in public roles, masculinity and dominating position. Therefore, good material should be balance. Between men and women must be balanced on different types of roles, properties, or a particular position. Natural, not contrived to train a child looking at the reality of men and women are equals. Explicit, the image or text reading between men and women have the same position. And repetition, the description of the role, nature, and equivalent position shown consistently and repeatedly.

c. Lexical Density

Lexical density is a measure of the amount of content information in a text. Lexical density is calculated by dividing the number of content words in a clause complex by the number of clauses in the complex. It means that the lexical density measures the density of information in any passage of text, according to how tightly the lexical items have been packed into the grammatical structure. This is a measure of how much information provided in a particular piece of writing. Lexical words are perhaps more commonly known as content words or information words. Nunan (in sholicatun, 2011: 15) stated that lexical density referred to the number of lexical content of function words per clause. Lexical density measures of the proportion of content words in a sentence or text. In addition, lexical density is a term used in discourse analysis. It is used to measure the ratio of content words to grammatical words in any given text.

d. Authenticity

According to Tatsuki (2006) stated that authenticity is taken as being synonymous with genuineness, realness, truthfulness, validity, reliability of materials. Furthermore, McDonald et al (2006) stated that if a correspondence occurs between the texts used by teachers in the classrooms and kinds of texts used in the real world, in this case, these texts can be regarded authentic. Mishan (2005) stated that there are three approaches which are regarded as the basis for the term authenticity in language teaching. These are communicative, materials focused, and humanistic approaches. Communicative approach, in this approach focus in communication from both sides (the learning process and the teaching method). Materials focused approach, the learning in this approach is text centered. Humanistic approach, this approach emphasized the unity of learners' feelings and the learning process.

From the aspect of good reading material, the researcher takes two aspects that are gender equality and readability. 


\section{Previous Study}

There are studies related with a content analysis on the quality of short stories in short stories. Firstly, a research done by Syafitri "Analysis Reading Materials On Look Ahead Textbook Of Tenth Grade Students By PT. Erlangga", the researcher used descriptive method with the purpose of the research was to describe reading materials in English textbook "Look Ahead" for Senior High School of tenth grade students fulfill the criteria of reading material or not, where the result of the findings show that reading materials in the textbook are appropriate with the criteria. There are five criteria of good reading materials, they are subject matter, vocabulary and structure, exercises, illustrations, and the last is physical make up. According to those criteria, the materials of reading in English textbook "Look Ahead" for senior high school of tenth grade students by PT. Erlangga are appropriate with the criteria of good reading material.

The last study research is a research done by Sholichatun (2011) "Content Analysis Of Reading Materials In English On Sky Textbook For Junior High School", the researcher used descriptive qualitative method with the purpose of the research was to find out the kind of genre contained in the reading passage

found in English On Sky textbook for 9th grade of junior high school published by

Erlangga, and find out the lexical density of reading text based on English On Sky textbook for 9th grade level of junior high school, the result of the research that the English on Sky textbook contained three genres. They are procedure, report and narrative. The dominant text on this book is report text. The writer found seven report texts. Furthermore, the writer found only one procedure text in this book. And From ten of the reading texts, there are three lower lexical densities (easily to be understood), seven quite lexical densities. However, there is no difficult to be understood, most of them have quite lexical densities. It means that the texts are not quite difficult to be understood.

\section{Research Method}

\section{Research Design}

Research design is a procedure in planning research. It is useful as a guide to build a strategy that result in the research model. According to John W. Creswell (2008:7), research is a process of steps used to collect and analyze information to increase our understanding of a topic or issue. The design of research is a descriptive qualitative research. Qualitative research is one of research procedures that produce the descriptive data, such as; utterance or written texts and people behavior that are observed (Creswell, John 2008:173). Qualitative research is descriptive since it is intended to analyze more on words than numbers and the findings of this research were reported in the form of statement. The study also 
adopts descriptive research. According to Burns and Grove (2003:201) descriptive research is designed to provide a picture of a situation as it naturally happens. It may be used to justify current practice and make judgement and also to develop theories. The objectives of this research are to measure the quality of short stories, to identify the readability of short stories, and to identify the gender equality of short stories book published by children's book trust.

\section{Data Sources}

The source data from this research taken from book entitled short stories for children's published by children's book trust. In this research, the researcher uses a documentation. Documentation is a way of collecting data dealing with the variables or things which have been written or printed in the form of short stories in children's book published by children's book trust. In this book consists of 17 titles from 17 authors.

\section{Research Instrument}

The writer is the instrument in the study. The writer is involved in the whole process of research, from getting permission to do the research, take the data from books, doing the research of the data, and making analysis

\section{Data Analysis method}

To find the result of this research, the researcher uses a content analysis. Content analysis is a method that may be used with either qualitative or quantitative data and in an inductive or deductive way. Cole (in satu elo \& helvi kyngas, 2008:107) stated that content analysis is method of analysis of written, verbal or visual communication message. There are two measure of content analysis such us the readability and gender equality. In readability, the ease of comprehension of short stories can measured using the Felsch Reading Ease Formula. The Felsch Reading Ease Formula is considered as one of the oldest and most accurate readability formulas. The Felsch Reading Ease Formula is a simple approach to assess the grade level of the reader. It is also one of the few accurate measures around that can rely on without too much scrutiny. This formula is best used on school text. This empirical test is based on the linguistic properties of the input text, such as the average number of words per sentence and the average number of syllables per word. The resulting readability scores range from 0 to 100 and can be interpreted as follows:

$$
R E=206-(1.015 \times \text { ASL) }-(84.6 \times \text { ASW })
$$

RE : Readability ease

ASL : Average sentence length

ASW : Average number of syllables per word

Table 1. The resulting readability scores

\begin{tabular}{l|l|l}
\hline Score & Reading Level & Grade \\
\hline $90-100$ & Easily understandable & Fifth Grader \\
\hline $60-70$ & Easily understood & Eighth and ninth \\
\hline
\end{tabular}




\begin{tabular}{l|l|l}
\hline $0-30$ & Easily understood & Collage graduats \\
\hline
\end{tabular}

The following table is also helpful to assess the ease of readability in a document:

$$
\begin{aligned}
& 90-100 \text { : very easy } \\
& 80-89 \text { : easy } \\
& 70-79 \text { : fairly easy } \\
& 60-69 \text { : standard } \\
& 50-49 \text { : fairly difficult } \\
& 0-29 \text { : very difficult }
\end{aligned}
$$

On the other hand in gender equality the researcher focus on the reading texts from the short story. The analysis using manual techniques by reading one by one of seventeen story title. If the story is not equality between male and female fiqures it means that the story is a gender bias. In a short story called gender bias if the contains of the story was to show the reading text that puts one gender is more dominant or likely to be described repeatedly on the type, character

\begin{tabular}{|c|c|c|}
\hline No. & Title of Short Stories & The Authors \\
\hline & Man Overboard & Vasantha Murthi \\
\hline & When Papa Scolded Me & Ira Saxena \\
\hline & To The Memory Of A Lion & Tara Tixoari \\
\hline & The Triumphant Smile & K.C. Batra \\
\hline & The Turkish Cap & B.P. Gupta \\
\hline & The Goose Thieves & Padmini Bannerjee \\
\hline & Christmas Bells & R.K. Murthi \\
\hline & In A Guava Orchard & N.P. Singh \\
\hline & All Because Of My Hair & S.G. Haidar \\
\hline 10. & The Pink Card & Indira Ananthakrishrwn \\
\hline 11. & The Unforgettable Journey & E. Sheila \\
\hline 12. & Varunkaka's Lemonade Pals & Valjayanti Savant Tonpe \\
\hline 13. & Hanuman And I & Rupa Gupta \\
\hline & At The Party & Anil Ektobe \\
\hline 15. & Outwitted & Tara Parameswaran \\
\hline 16. & That Sunday Morning & Savita Singh \\
\hline 17. & The Boy From Standard III & Pratibha Nath \\
\hline
\end{tabular}
or certain positions

\section{Research Finding and Discussion}

In this part contains the data presentation from short stories as can be seen below:

Table 2. The Data Presentation

\section{Result of Gender}

To analyze the readability, this analysis used Felsch Reading Ease Formula. There are three types in this formula such as readability 
consensus, word statistics, and graph statistics. Readability consensus was to know the grade level, level of reading, and readers age. Word statistics were to know about total of words, total of unique words, total of repeat words, average of words per sentence, total of sentences, total of characters, average of characters per word, average of syllables per word, total syllables in text, total of words with double syllable, percent of double syllables in text, total words with single syllables, percent of single syllables in text, percent of 3 syllables in text, and total of words with 3 syllables.

In this part the researcher described about the result of readability. The first title is Man Overboard. This story can be read by children's from fourth grade, especially children's aged eight and nine years. The reading level from this story is easy to read. The second title is When Papa Scolded Me. The third is to The Memory of a Lion. And the fourth is The Triumphant Smile. The stories are same as the first story that can be read by children's from fourth grade, especially children's aged eight and nine years. The reading level from this story is easy to read. The fifth is The Turkish Cap. This story can be read by children's from third grade, especially children's aged eight and nine years. The reading level from this story is very easy to read. The sixth is The Goose Thieves. This story can be read by children's from fifth grade, especially children's aged ten and eleven years. The reading level from this story is easy to read. The seventh, eight, and eleventh titles are same from the fifth title. This stories can be read by children's from third grade, especially children's aged eight and nine years. The reading level from this story is very easy to read. The ninth, thirteenth, fifteenth, and sixteenth are same from the sixth title. This stories can be read by children's from fifth grade, especially children's aged ten and eleven years. The reading level from this story is easy to read. The tenth title is different from the other titles. This story can be read by children's from second grade, especially children's aged six until eight years. The reading level from this story is very easy to read. Then, the twelfth, fourteenth, and seventeenth are same from the first title. This stories can be read by children's from fourth grade, especially children's aged eight and nine years. The reading level from this story is easy to read (see appendix 5). Based on the result the score of readability ease and word statistics can be seen in appendix 4

\section{Discussion}

The purposes of this research are to measure the quality of short stories in short stories for children's, to identify the readability and gender equality in short stories for children's published by children's book trust. Based on the result on short stories, all of short story can be read by children from the age 8 - 11 years old. From the 17 short stories there two types of reading level such as easy and very easy. From the 17 short stories there are 13 short stories that criteria of reading level is easy. While the other four short stories is very easy. And in gender, character between male and female not balance. Some short stories only tell on one gender. From the result of gender equality 
and readability, this short story is enough to be an reading children's book

\section{E. Conclusion}

The findings reported in the four chapter discussed previously have given us a description about the result of this research. Here, the researcher draws some concluding remarks based on the statements of the problem of this research. They are:

1. The researcher concluded that the quality of short stories for children's published by children's book trust is enough.

2. The readability of short stories in short stories for children's published by children's book trust is easily understood by children's and all short stories are suitable as children's books.

3. The gender equality in short stories for children's published by children's book trust is gender bias. The short stories only focus on one gender.

\section{F. Acknowledgement}

First of all, I would like to thank to Allah SWT, for giving me time, chance, health to finish this thesis on time. My special thanks to my greatest consultants, Abdul Munir, M.Pd. and Tri Mulyati, M.Pd. who have kindly guided me with care and allowed me to profit from their advice in writing this thesis.

My Thanks also due to the following people:

1. Drs. H. Teguh Sumarno, MM, as the Rector of UNIBA Banyuwangi.

2. Abdul Munir, M.Pd, as the Dean of Language and Art Faculty of University of Banyuwangi.

3. Wulan Wangi, M.Pd as the Head of English Education Department of PGRI University of Banyuwangi.

4. All my families who supported me. Thanks for everything.

5. All my Lectures and Staffs of English Education Department at PGRI University of Banyuwangi.

6. All my friends at PGRI University of Banyuwangi, especially from the English Education Department.

7. All people who helped me are finishing this thesis

I realize that this thesis is far for being perfect without their precious comment and critics. Therefore, I will be grateful to have other from all readers.

\section{G. Reference}

Ali, Omar et all. 2010. Automating News Content Analysis:An Application to Gender Bias and Readibility.UK.Workshop and Conference Proceedings.

Burn, SN \& Grove. SK. 1997. The Practice of Nursing Research. 3rd edition. Philadelphia : Saunders.

Creswell, John W. 2008. Qualitative Inquiry and Research Design. Third Edition. California : Sage Publication.

Elo, S \& Kingas H. 2008. The Qualitative Content Analysis Process. Finland: Journal of Advanced Nursing. 
Fauziati, Endang. 2009. Reading on Applied Linguistics : A Handbook for Language Teacher and Teacher Researcher. Surakarta : PT. Era Pustaka.

Jenis - jenis Cerpen. http://tentangceritapendek.wordpress.com. Retrieved on $25^{\text {th }}$ September 2012.

Lexical Density. http://wiki.answer.com/Q/what is lexical density. Retrived on 10th july 2010.

MacDonald, M.N. \& Badger, R. Dasli, M. 2006. Authenticity, Culture and Language Learning. Language and Intercultural Communication Vol. 6, No. 3 \& 4. Pp 250-26.

Mishan, F. 2005. Designing Authenticity Into Language Learning Material. Bristol.

Readability formula. http://www.readabilityformulas.com/flesch-readingease- readability-formula.php.

Sholicatun, Siti. 2011. Content Analysis of Reading Materials in English On Sky Textbook for Junior High School. Semarang : Institut Agama Islam Negeri Walisongo.

Tatsuki, D. 2006. What is authenticity? the language teacher, 16(5), 17-21. Retrieved from http://jalt.org/pansig/2006/HTML/Tatsuki.htm.. 